\title{
Endovascular repair for blunt thoracic aortic injury: A safe and durable procedure
}

\author{
Cipriano Abad, MD
}

See related article on pages 2956-61.

The article by Spiliotopoulos and colleagues ${ }^{1}$ from the Department of Cardiothoracic Surgery, Stanford University Medical Center, California, is an interesting retrospective clinical review. The authors evaluated 76 cases of thoracic endovascular aortic repair (TEVAR) for blunt thoracic aortic injury (BTAI) over an 11-year period (2012-2013). Technical success was achieved in $93 \%$ of cases and allcause mortality was $11 \%$. No patient required conversion to an open thoracotomy. The long-term outcome in the 60 survivors was good without any stent graft or cardiovascular complications. The patients were divided into 2 groups: group 1 included 36 patients who were followed up within 6 months of their scheduled yearly visit and group 2 , which consisted of 24 patients whose follow up was delayed more than 6 months after their scheduled yearly visit. The authors found no difference in the late results between the groups and concluded that delays in surveillance could be beneficial because of the reduced cumulative risk of irradiation by repeated computed tomography scans.

Midterm outcomes of TEVAR for BTAI suggest that the repair was stable. The authors recommend larger multicenter randomized studies to establish the most appropriate surveillance schedule for stable patients.

At present, TEVAR is considered the gold standard treatment for BTAI. Since the first case reports published by Semba and colleague, ${ }^{2}$ many publications have reported good results with the endovascular approach. Tang and colleagues, ${ }^{3}$ in a meta-analysis of 33 publications on BTAI, found a lower incidence of mortality, stroke, and paraplegia in the patients managed by TEVAR. To establish their guidelines, the Society of Vascular Surgery ${ }^{4}$ reviewed 139 publications reporting 7768 cases of BTAI, and they concluded that TEVAR provided better outcomes than open repair.

This article is significant and worthy of the attention of the readers of the Journal of Thoracic and Cardiovascular Surgery. The text is well written and the study includes a large number of patients and demonstrates that excellent results can be obtained with TEVAR. The authors conclude that routine surveillance can be safely extended beyond the scheduled yearly examination. However, the authors should provide a recommendation about the most appropriate surveillance interval for stable patients.

\section{References}

1. Spiliotopoulos K, Kokotsakis J, Argiriou M, Dedeilias P, Farsaris D, Charitos C, et al. Endovascular repair for blunt thoracic aortic injury: 11-year outcomes and postoperative surveillance experience. J Thorac Cardiovasc Surg. 2014;148: 2956-61.

2. Semba CP, Kato N, Kee ST, Lee GK, Mitchell RS, Miller DC, et al. Acute rupture of the descending thoracic aorta: repair with use of endovascular stent-grafts. $J$ Vasc Interv Radiol. 1997;3:337-42.

3. Tang GL, Tehrani HY, Usman A, Katariya K, Otero C, Perez E, et al. Reduced mortality, paraplegia, and stroke with stent graft repair of blunt aortic transections: a modern meta-analysis. J Vasc Surg. 2008;47:671-5.

4. Lee WA, Matsumura JS, Mitchell RS, Farber MA, Greenberg RK, Azizzadeh A, et al. Endovascular repair of traumatic thoracic aortic injury: clinical practice guidelines of the Society for Vascular Surgery. J Vasc Surg. 2011;53:187-92.

\footnotetext{
From the Hospital Universitario de GC Dr Negrin, Las Palmas de Gran Canaria, Spain.

Disclosures: Author has nothing to disclose with regard to commercial support.

Received for publication Sept 16, 2014; revisions received Sept 24, 2014; accepted for publication Sept 27, 2014; available ahead of print Oct 22, 2014.

Address for reprints: Cipriano Abad, MD, CardioVascular Surgery, Hospital Universitario de GC Dr Negrin, Barranco de la Ballena s/n, 350020 Las Palmas de Gran Canaria, Spain (E-mail: cprnabad2@gmail.com).

J Thorac Cardiovasc Surg 2014;148:2962

$0022-5223 / \$ 36.00$

Copyright (c) 2014 by The American Association for Thoracic Surgery

http://dx.doi.org/10.1016/j.jtcvs.2014.09.114
} 